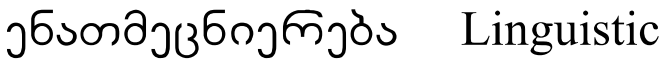

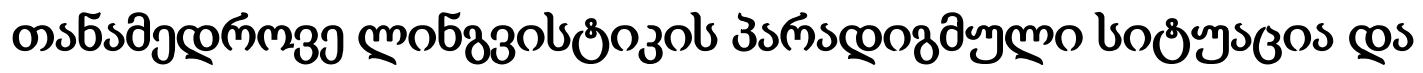

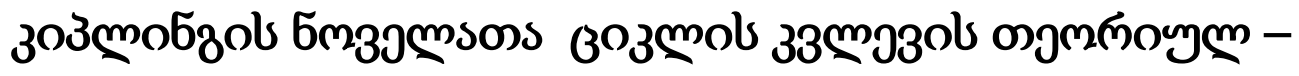

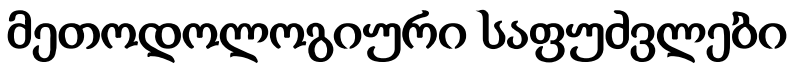

https://doi.org/10.52340/lac.2021.659

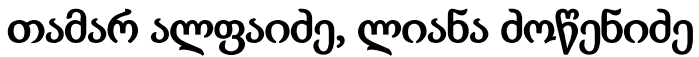

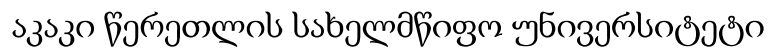
e-mail:tamunaalpaidze@gmail.com

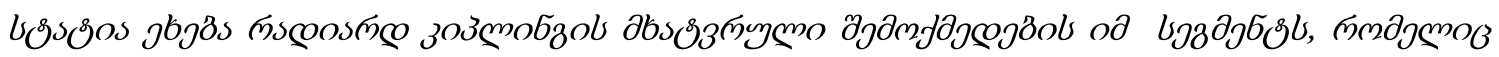

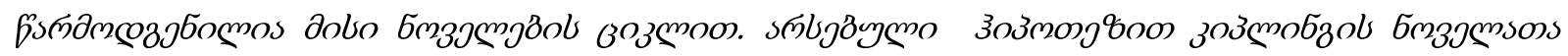

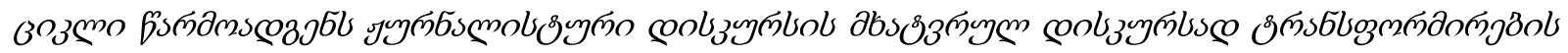

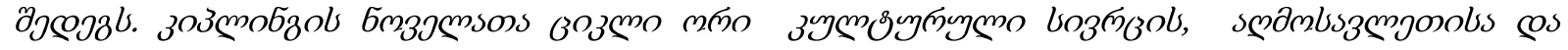

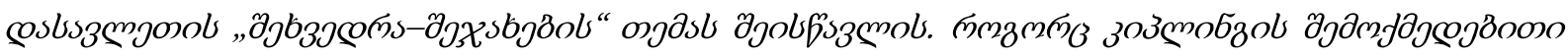

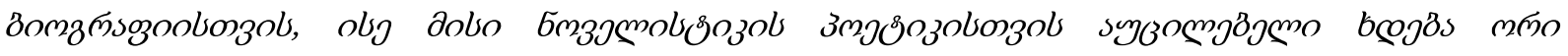

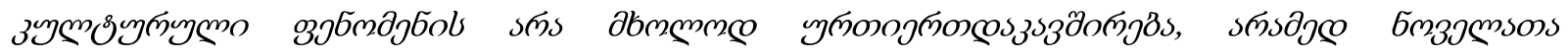

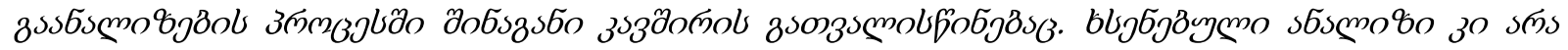

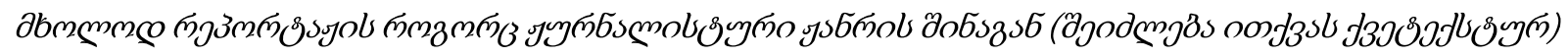

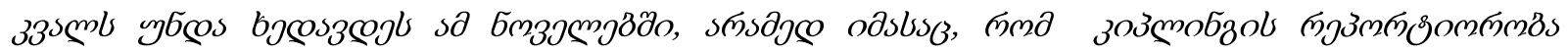

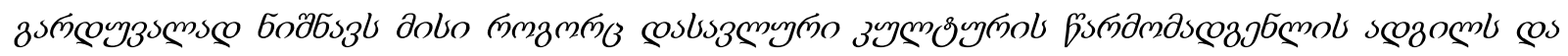

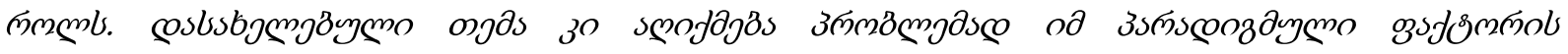

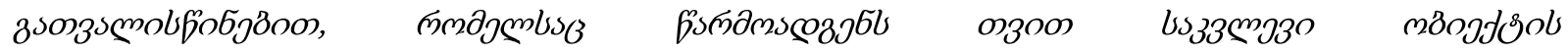




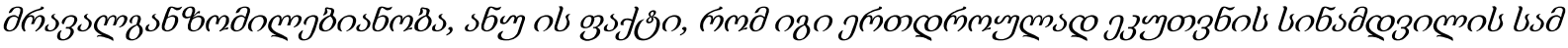

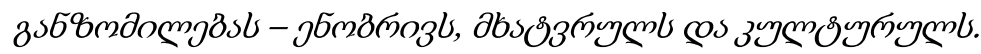

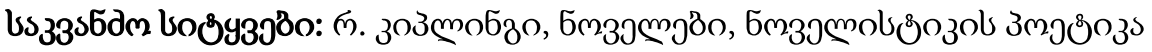

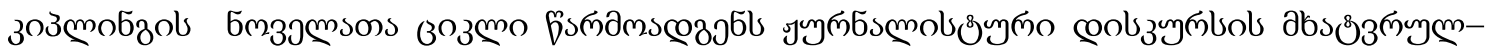

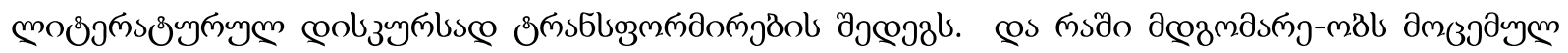

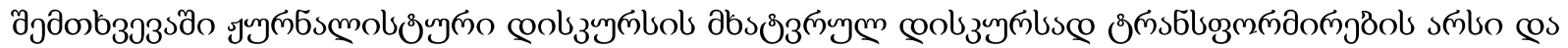

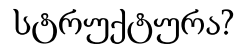

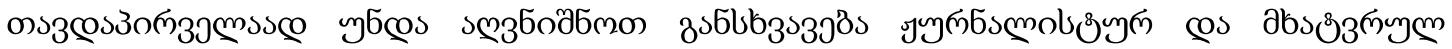

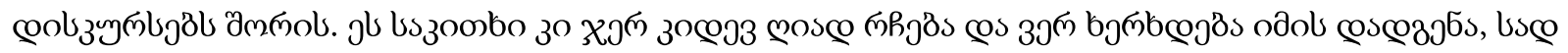

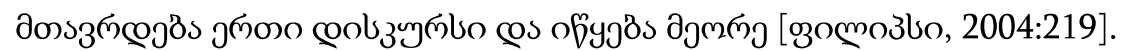

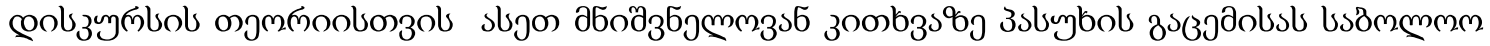

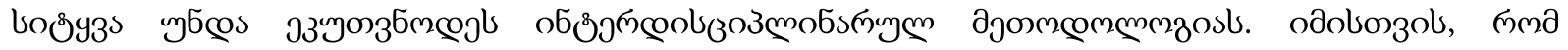

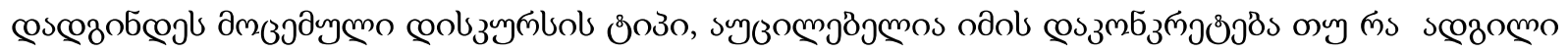

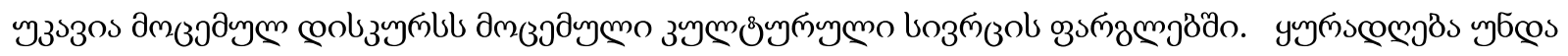

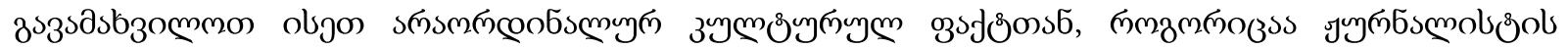

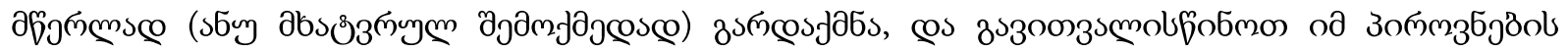

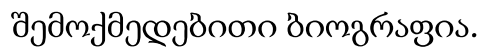

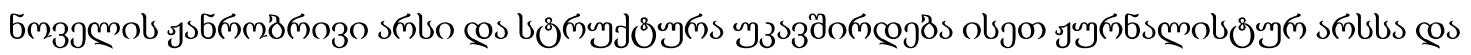

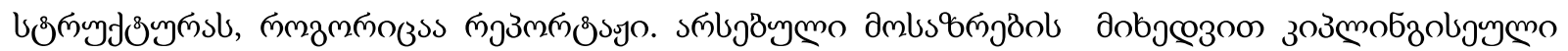

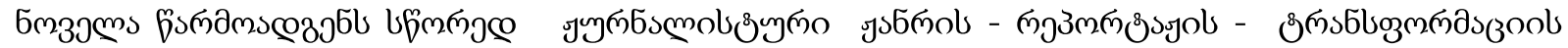

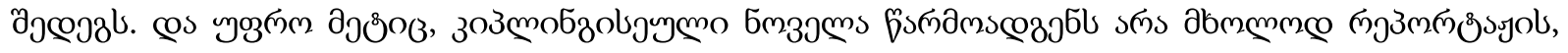

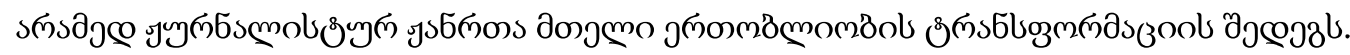

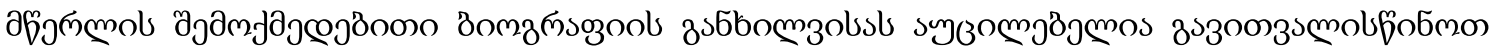

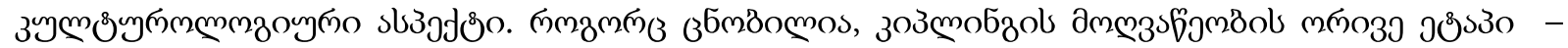

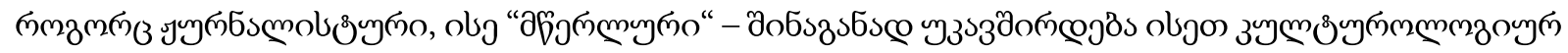

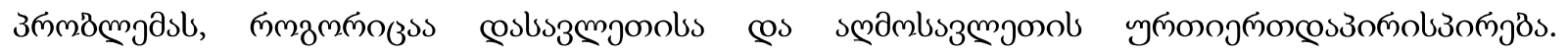




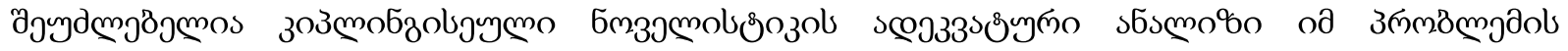

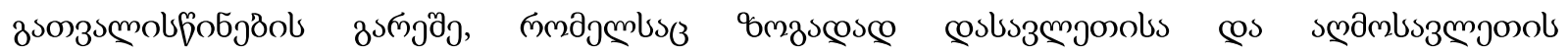

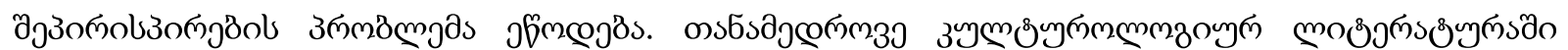

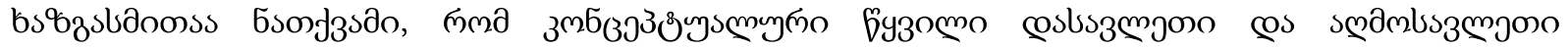

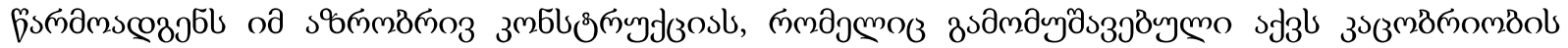

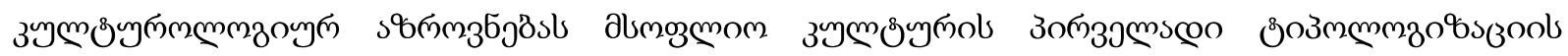

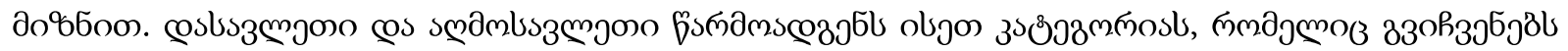

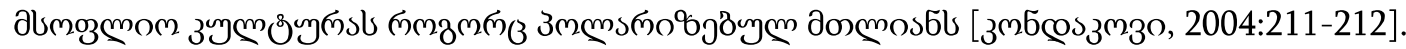

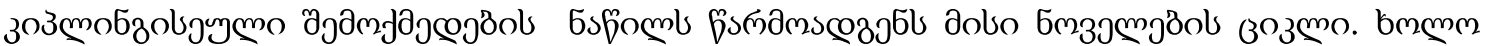

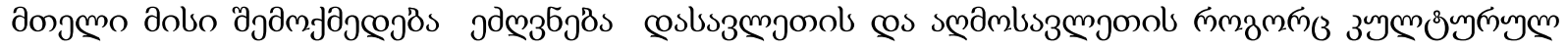

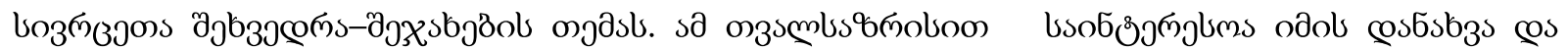

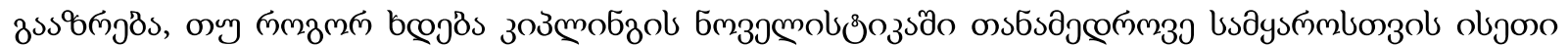

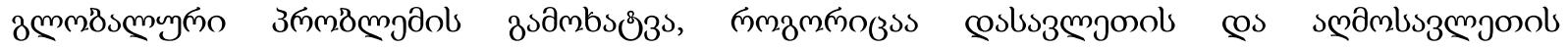

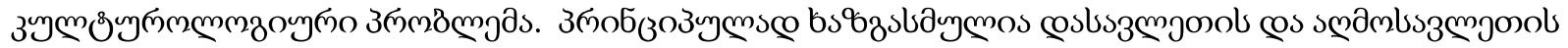

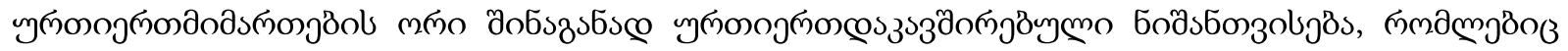

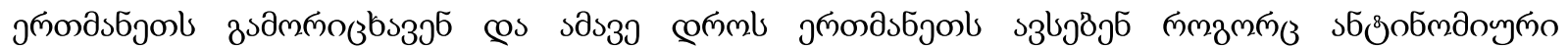
змmsтrnymo bsfyolgöo.

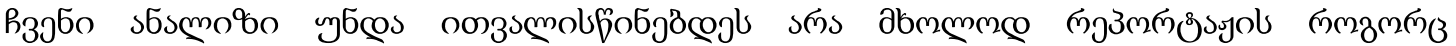

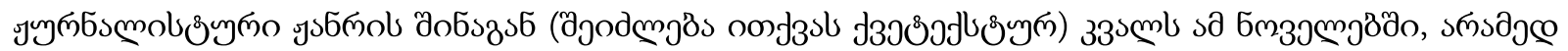

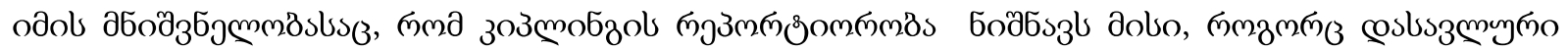

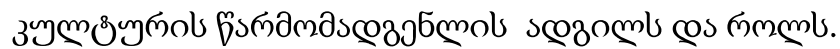

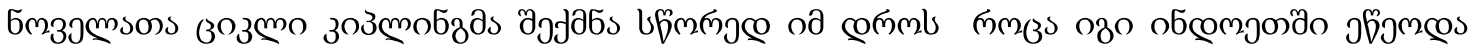

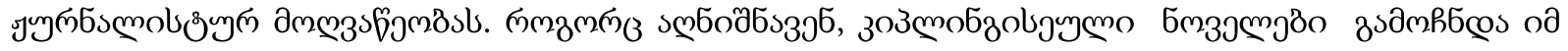

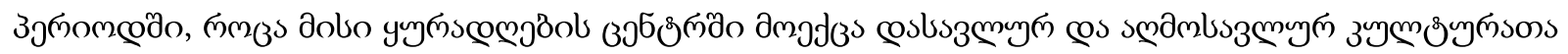

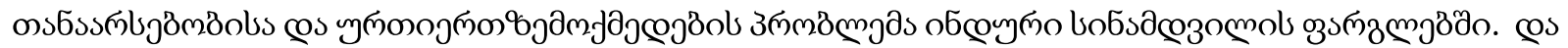

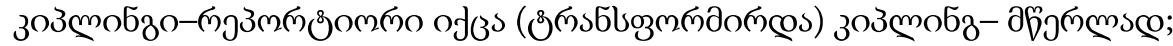

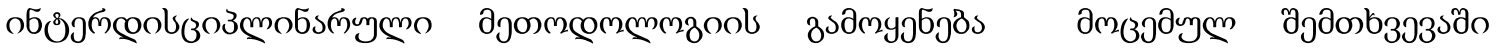

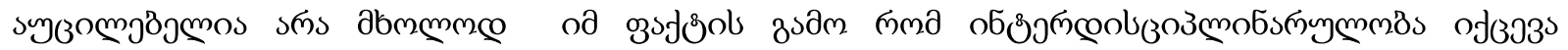




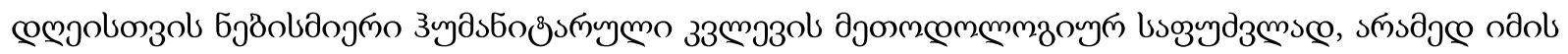

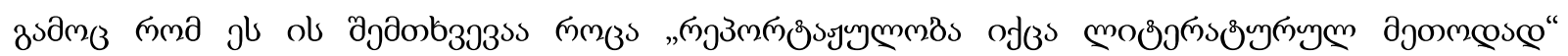
[зозмобзо,1983:17].

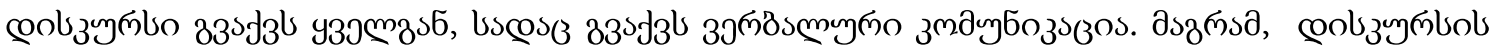

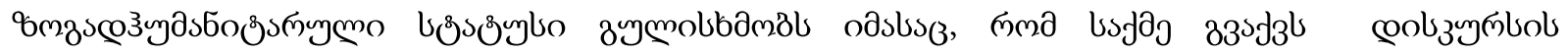

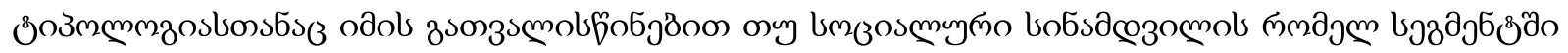

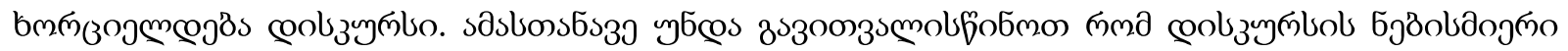

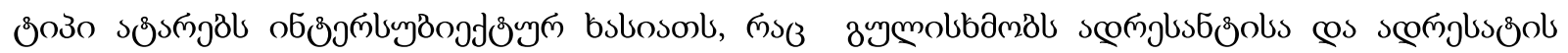

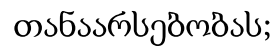

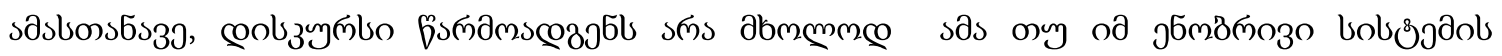

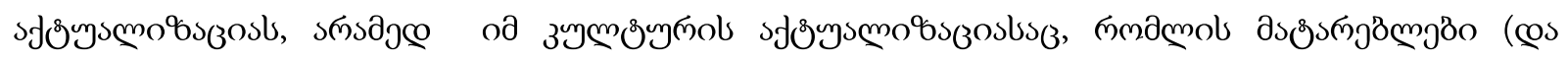

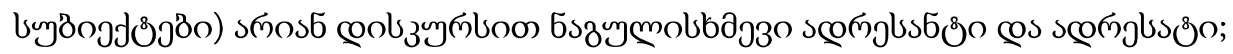

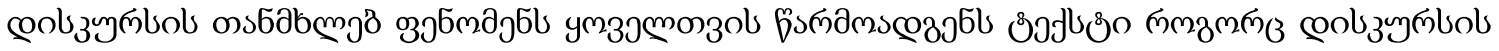

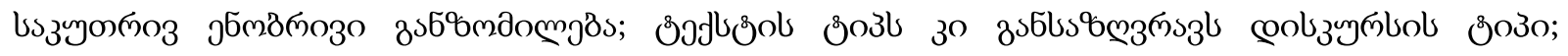

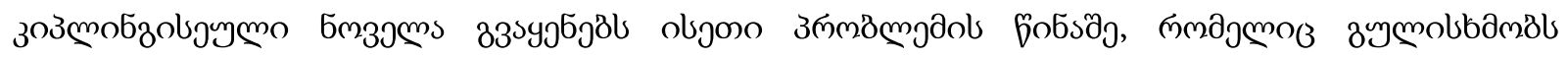

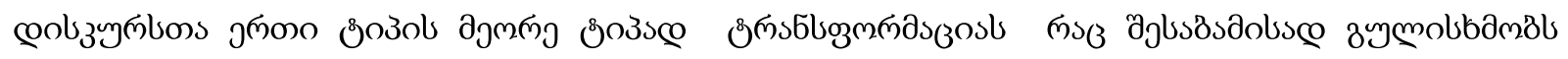

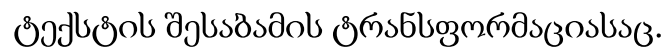

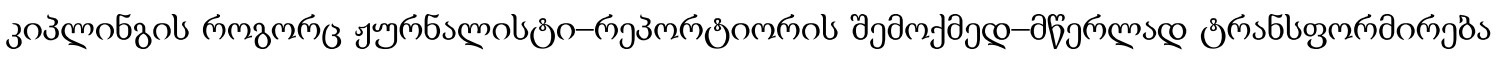

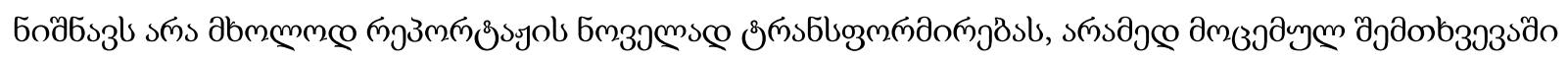

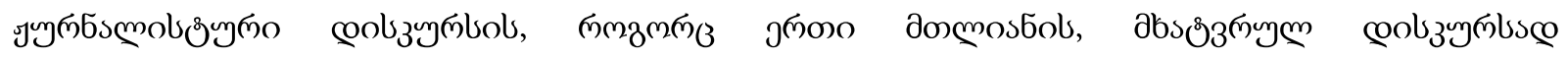

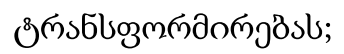

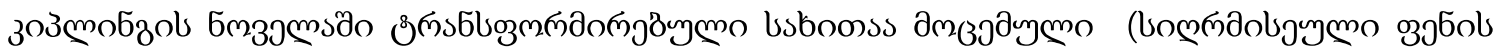

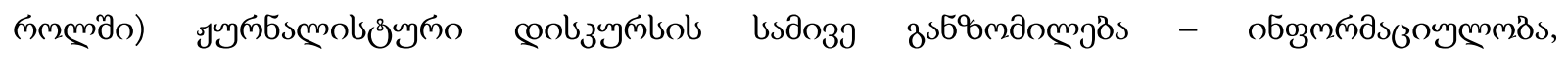

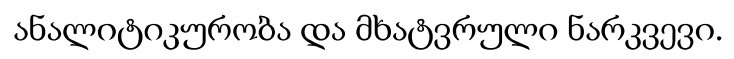

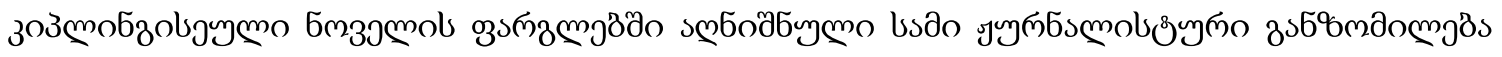

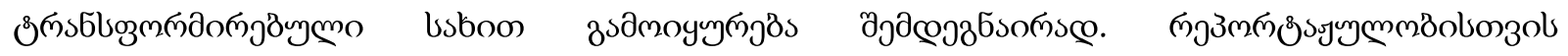

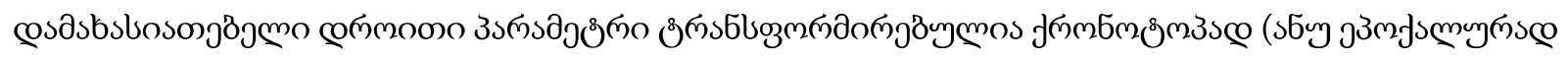

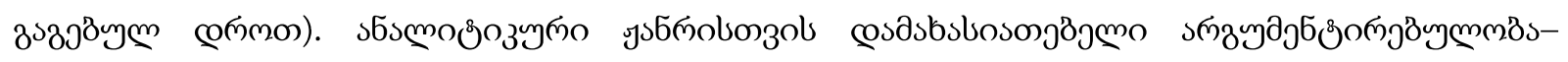




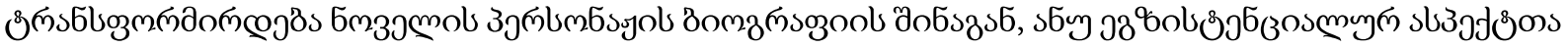

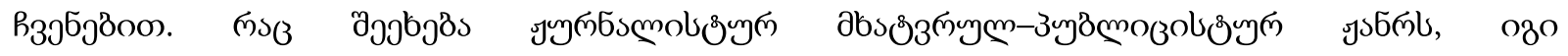

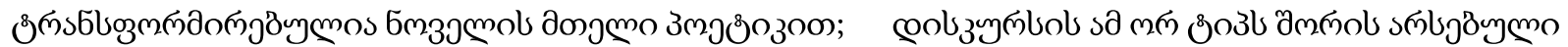

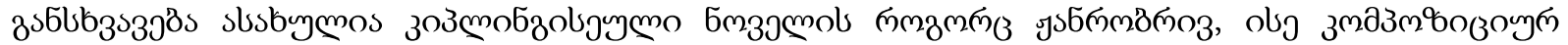

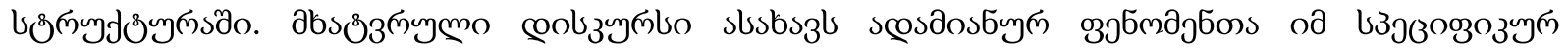

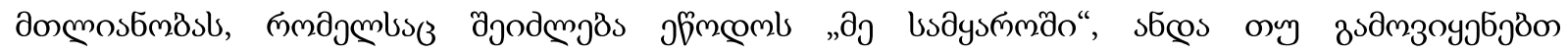

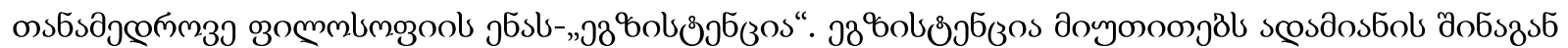

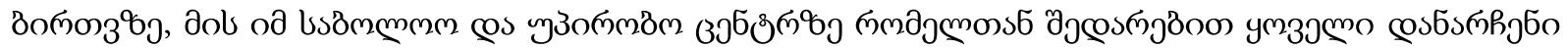

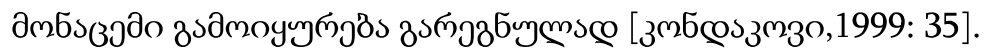

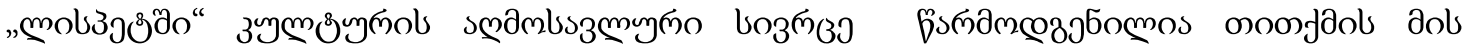

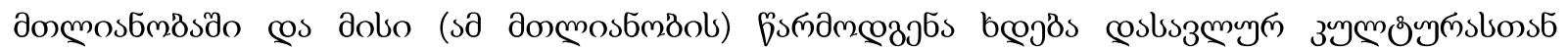

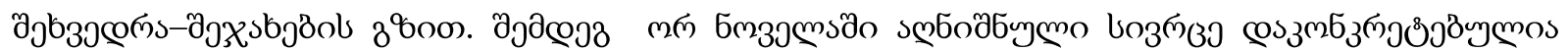
ซృдৎэзо Бодбоо:

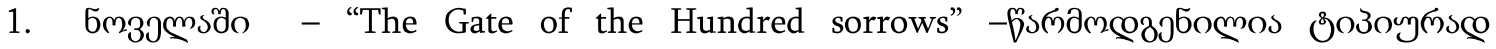

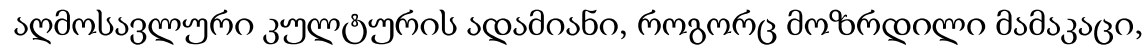

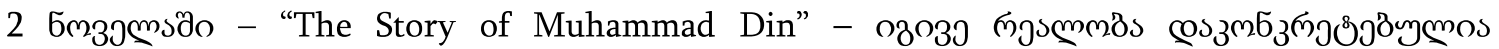

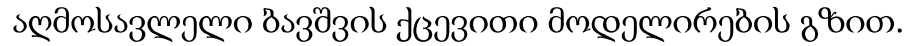

"He dropped bazar-rum and took to the Black Smoke instead".

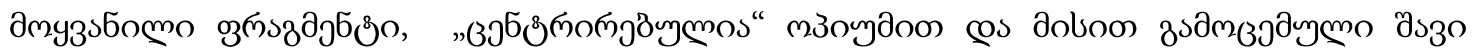

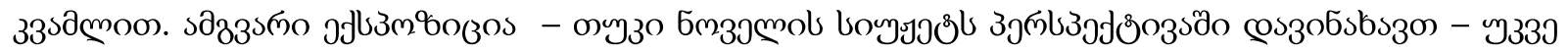

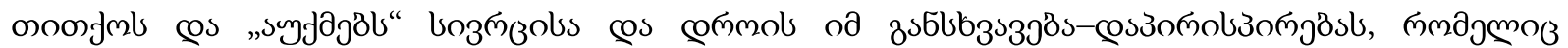

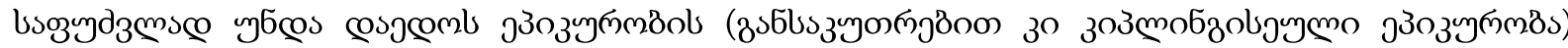

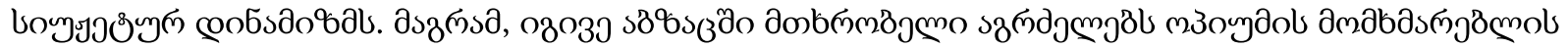

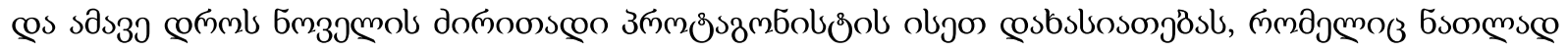

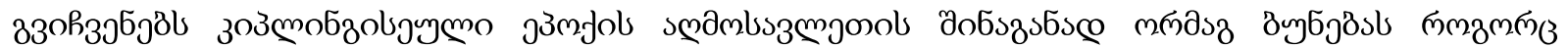

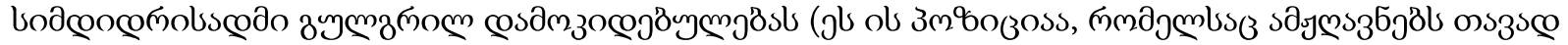

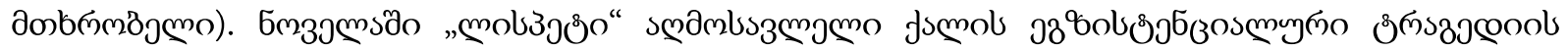

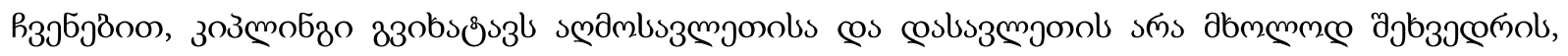




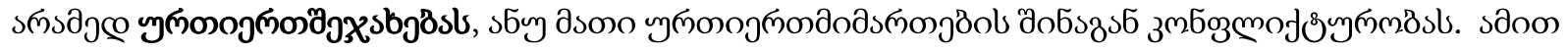

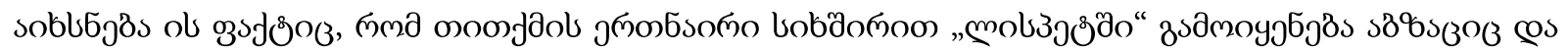
өзмпзгов.

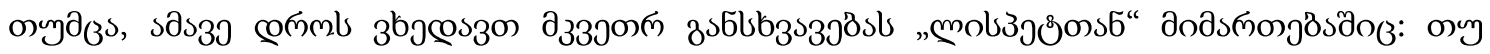

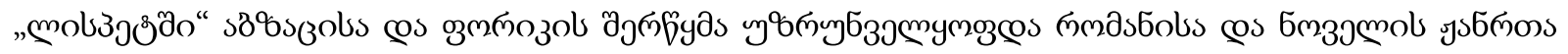

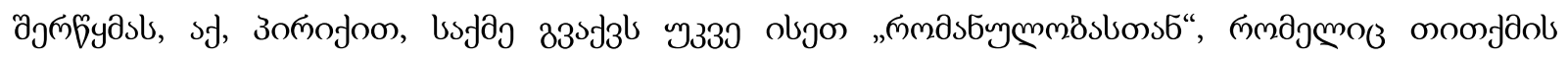

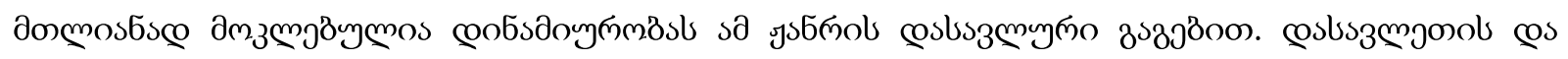

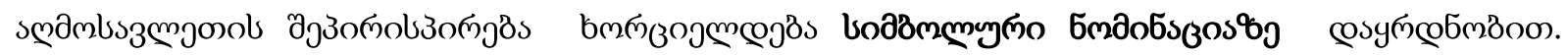

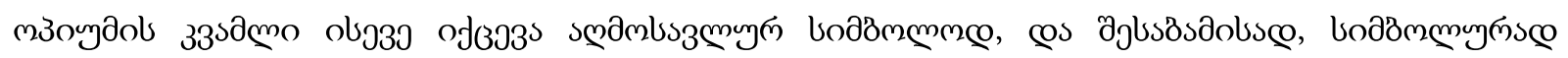

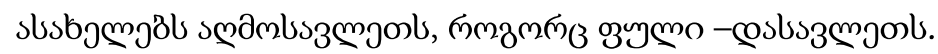

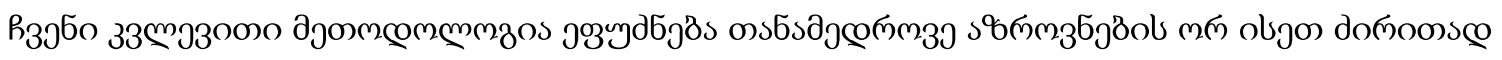

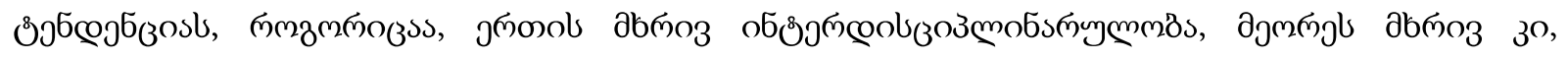

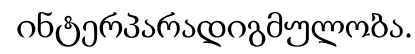

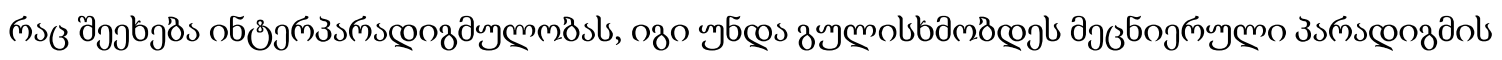

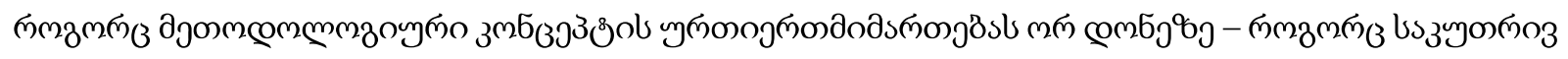

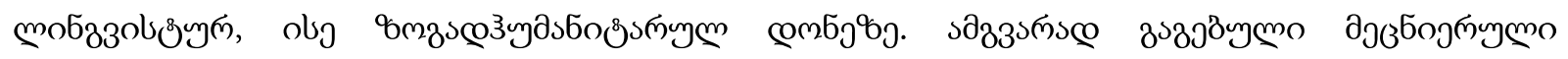

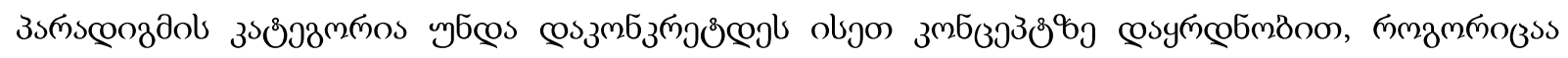

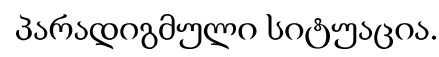

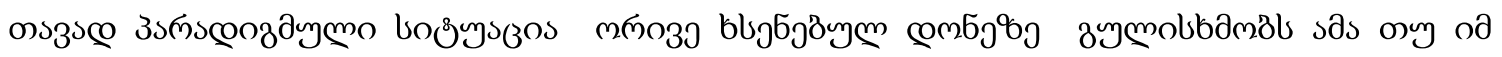

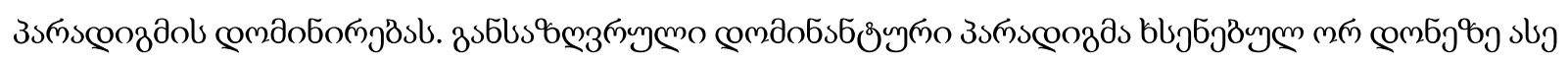

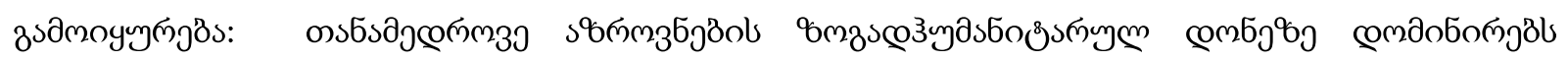

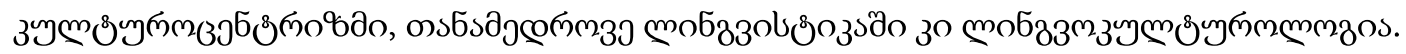

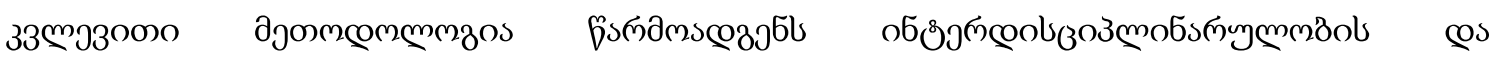

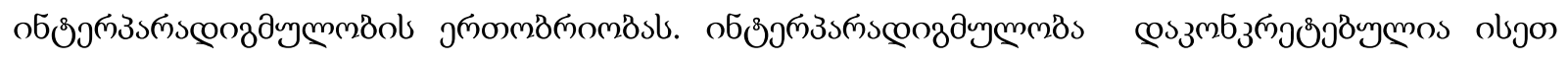

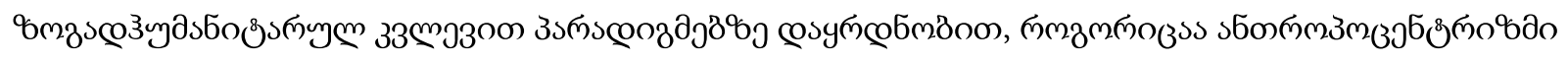

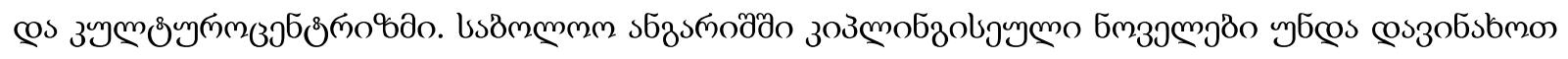

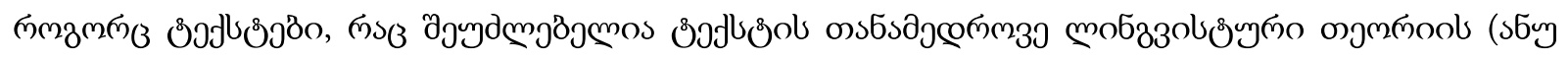

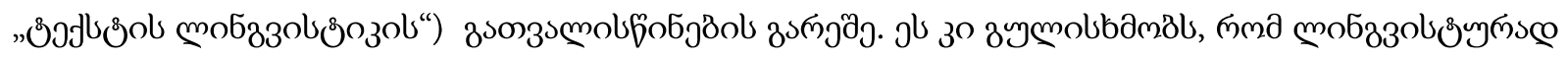




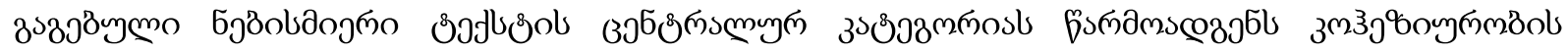

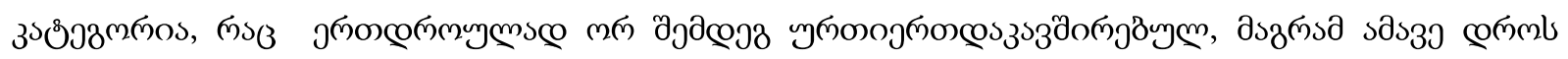

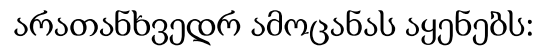

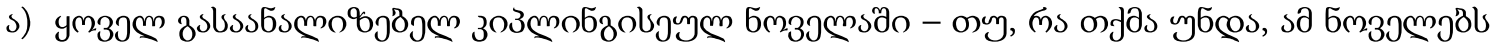

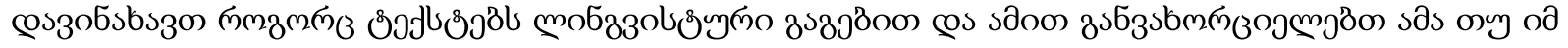

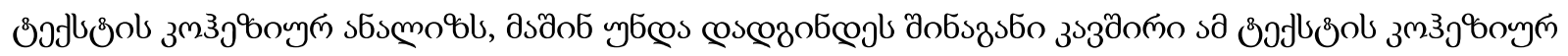

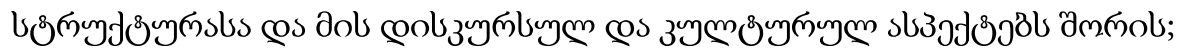

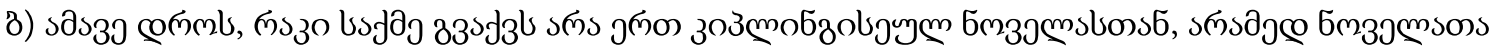

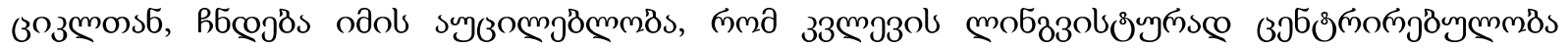

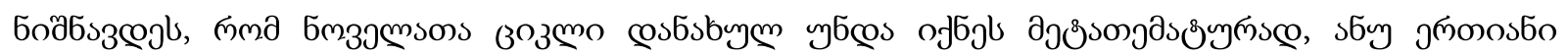

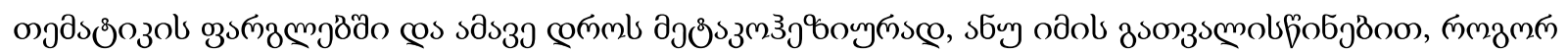

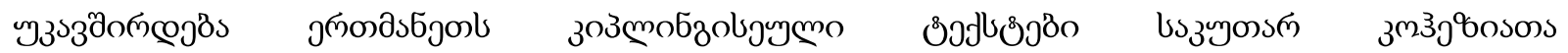

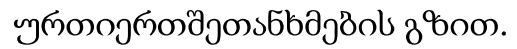

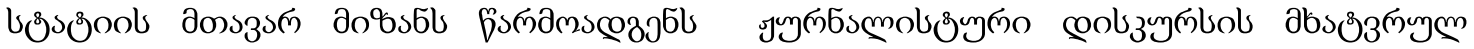

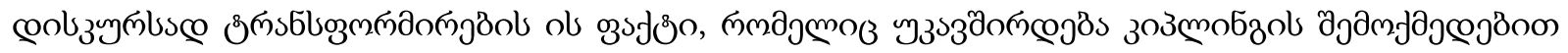

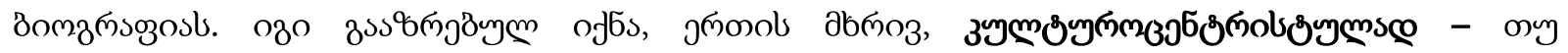

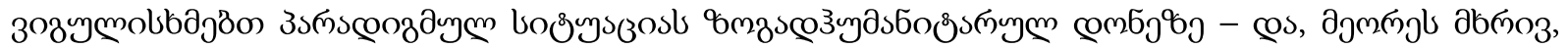

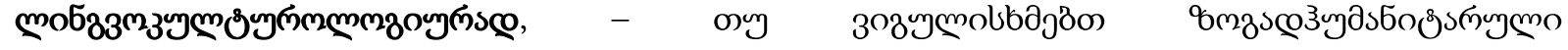

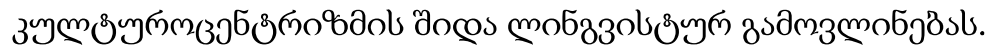

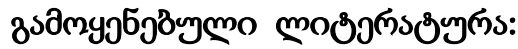

1. зозмобдо ๓๓., - Short stories, Moscow,Raduga Publishers (1983)

2. змбюозмзо з., - Речептивная эстетика Западное Литератураведение XX Века Intrada, Москва(2004)

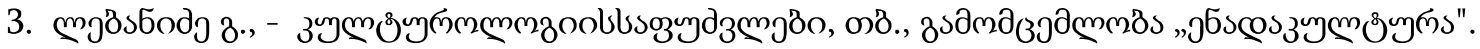

4. эомољ孔о Ł., - Дискурс-анализ. (Телория и метод. Харьков.2004 
Tamar Alpaidze, Liana Dzotsenidze

Akaki Tsereteli State University

\title{
Short story poetics and theoretical and methodological bases of research into \\ Kipling's short story cycle
}

\begin{abstract}
According to the recent hypothesis, Kipling's short stories are considered to be the products of the transformation of journalistic discourse into a literary one. Kipling's short stories deal with the topic of "clashes" of Western and Eastern cultures. Linking these two cultural phenomena is an essential factor in his biography as well as poetics of his short stories and their internal connection needs to be considered in the analysis of the stories. This analysis should not only identify the traces of a report as a journalistic genre (even if at the level of subtext), but also confirm that Kipling's work as a reporter implies his role as a representative of the Western culture. The given topic can be perceived as a problem due to the paradigmatic factor represented by its multidimensional nature i.e. the fact that it belongs to three dimensions of reality - linguistic, fictional and cultural.
\end{abstract}

Key words: R. Kipling, short stories, the poetics os short stories

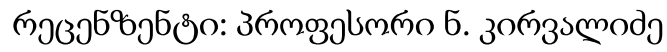

